\title{
An Electrospray Ionization Study of Some Novel Alkylamine Thiohydantoin Amino Acid Derivatives
}

\author{
Cecilia Basic, ${ }^{*}$ Jerome M. Bailey, ${ }^{\dagger}$ and Terry D. Lee \\ Division of Immunology, Beckman Research Institute of the City of Hope, 1450 East Duarte Road, \\ Duarte, California, USA
}

\begin{abstract}
An electrospray ionization-mass spectrometric (ES-MS) study of some novel alkylamine thiohydantoin amino acid derivatives is presented. The alkylamine derivatives are being developed as part of an on-going effort to couple an Edmanlike protein sequencer to a bench-top electrospray ionization (ES) mass spectrometer. The ES-MS and capillary-skimmer collision-induced dissociation (CID) mass spectra of eight dimethylaminopropylthiohydantoin (DMAP-TH) amino acid derivatives as well as the trimethylaminopropylthiohydantoin (TMAP-TH), diethylaminopropylthiohydantoin, and dibutylaminopropylthiohydantoin (DBAP-TH) derivatives of Phe are presented. The spectra contain prominent $[\mathrm{M}+\mathrm{H}]^{+}$ions as well as fragment ions due to the loss of the respective neutral alkylamines. The CID spectrum of DMAP-TH-Phe also contains the dibutylaminoethyl cation. The relative responses of the alkylamine thiohydantoin derivatives obtained under identical solvent conditions are found to increase as the solvophobicity of the amino acid $R$ group increases; the most solvophobic DBAP-TH-Phe gives rise to the highest overall response. DMAP-TH-Phe and the quaternary amine derivative TMAP-TH-Phe have comparable sensitivities when a sufficiently acidic solvent $(\mathrm{pH}=3)$ is employed. Implications of these studies in the coupling of a protein sequencer to an ES mass spectrometer are discussed as are the requisite modifications of a single quadrupole mass spectrometer for ES analyses. ( $/$ Am Soc Mass Spectrom 1995, 6, 1211-1220)
\end{abstract}

$\mathrm{T}$ The use of mass spectrometry as an alternative method to high-performance liquid chromatography (HPLC) for the detection and identification of the amino acid derivative end-products of automated protein sequencing analyses has long been of interest [1-11]. Mass spectrometry offer several advantages over HPLC, which include increased sensitivity and speed and the ability to identify the amino acid derivatives based on their mass-to-charge ratios $(\mathrm{m} / \mathrm{z})$. Previous interests in coupling Edman N-terminal protein sequencers $[12-15]$ to mass spectrometers have lead to the mass spectrometry characterization of the phenylthiohydantoin $(\mathrm{PTH})$ amino acid derivatives via electron ionization (EI) [1-3], chemical ionization (CI) [4], gas chromatography-mass spectrometry (GC-MS) [5], and HPLC mass spectrometry (HPLC-MS) via thermospray ionization [6]. Efforts also have been focused on the mass spectrometry detection and characterization of other amino acid species formed during the

Address reprint request to Dr. Terry D. Lee, Division of Imm unology, Beckman Research Institute of the City of Hope, $1450 \mathrm{E}$. Duarte Road, Duarte, CA 91010-0269.

- Current address: Department of Chemistry, Villanova University, Villanova PA 19085.

+ Current address: Hewlett Packard Co., Protein Chemistry Systems, 1601 S. California Avenue, Palo Alto, CA 94304.
Edman degradation process that include the thiazolinone $[4,7]$ and the thiourea $[8]$ amino acid derivatives. Mass spectrometry analyses of the thiohydantoin amino acid derivatives also have been performed due to the potential role of these derivatives in possible C-terminal sequencing techniques [9-11].

Interest in the development of novel protein sequencing chemistries similar to that of the Edman degradation method [12,13], but which lead to amino acid end-products more amendable to mass spectrometry analyses, has resulted in a thioacetylation method of sequencing by using a gas chromatography-quadrupole ion trap mass spectrometer for detection of the resultant 2-benzoyl-5-O-(4'-nitrobenzene)sulfonylthiazole derivatives [16]. Although these end-products could be detected at the 20 -fmol level, off-line analysis of only one twentieth of the volume of the sample that resulted from each sequencing cycle was required for analysis due to the limitations of the GC-MS injection port [16]. Another approach in the development of novel sequencing methods based on electrospray (ES) mass spectrometry detection involves the use of a new Edman-type reagent, 4-(3-pyridinylmethylaminocarboxypropyl) phenyl isothiocyanate (PITC 311) [17, 18], which acts as an alternative to the phenylisothiocyanate (PITC) coupling agent currently 
used in Edman degradation methods [12-15]. Peptide degradation that used PITC 311 gave rise to the corresponding 4-(3-pyridinylmethylaminocarboxypropyl) PTH amino acid derivatives (PTH 311), that is, the phenyl group of the PTH has been derivatized with an ES-active functional group. The PTH 311 end-products showed detection limits in the low femtomole range when analyzed in the single ion monitoring mode (SIM) on a triple quadrupole mass spectrometer (TQMS) [17], comparable to those found for the quaternary ammonium derivatives 3-[4'-(ethylene- $N, N, N$-trimethylamino)phenyl]-2-thiohydantoins previously developed by the same group [19]. Moreover, the PTH 311 derivatives that resulted from the sequence analyses of synthetic peptides could be successfully identified by using on-line high-performance liquid chromatography-electrospray ionization mass spectrometry (HPLC-ES/MS) analysis $[17,18]$.

We present an electrospray ionization-mass spectrometry (ES-MS) study of a series of novel alkylamine thiohydantoin amino acid derivatives developed as part of an on-going effort to couple a protein sequencer to an ES mass spectrometer [20-22]. The alkylamine thiohydantoin derivatives are structurally similar to the PTHs, but unlike the PTH 311 derivatives, the phenyl group has been replaced by an ES-active tertiary or quaternary alkylamine. Electrospray was the ionization method of choice in these efforts due to the high sensitivity, small requisite sample sizes, and low solvent flow rates that ES can accommodate. The study was performed via a single quadrupole mass spectrometer because future sequencer-ES-MS systems will be based on a bench-top instrument. The study includes the ES-MS and capillary-skimmer collision-induced dissociation (CID) mass spectra of the dimethylaminopropylthiohydantoin (DMAP-TH) derivatives of glycine (Gly), valine (Val), leucine (Leu), isoleucine (Ile), aspartic acid (Asp), histidine (His), phenylalanine (Phe), and tyrosine (Tyr) (Table 1 ), the relative responses of these eight derivatives under identical spray conditions are included. Preliminary studies of the relative responses of the trimethylaminopropyl(TMAP-TH), diethylaminopropyl- (DEAP-TH), and dibutylaminopropylthiohydantoin (DBAP-TH) derivatives of Phe are also presented.

\section{Experimental}

\section{Sample Preparation}

Synthesis of the DMAP-TH, TMAP-TH, DEAP-TH, and DBAP-TH amino acid derivatives is described in detail elsewhere [20]. Briefly, the DMAP-TH, DEAP$\mathrm{TH}$, and DBAP-TH derivatives were formed from a condensation reaction in which the L-amino acid methyl esters $\cdot \mathrm{HCl}$ underwent nucleophilic addition followed by ring closure with the respective DMAP-, DEAP-, and DBAP-isothiocyanates. The TMAP-TH-Phe derivative was formed by methylation of DMAP-TH-Phe.
High purity PTH-Phe was purchased from Sigma Chemical Corp. (St. Louis, MO). Solutions were prepared by serial dilution of stock solutions prepared by dissolving $0.5-1.5 \mathrm{mg}$ of the samples in $50 \%$ (by volume) methanol and water with $1 \%$ (by volume) of acetic acid. The $\mathrm{pH}$ of the solutions was approximately 3. Sample concentrations were confirmed from the UV absorption spectra measured at $269 \mathrm{~nm}$. All reagents were of HPLC grade (E.M. Scientific, Gibbstown, NJ) and the water was produced by a Millipore Milli-Q purification system (Millipore, Bedford, MA).

\section{Electrospray Mass Spectra}

ES mass spectra of the amino acid derivatives were obtained using a Hewlett-Packard (Palo Alto, CA) 5970 MSD quadrupole mass spectrometer modified for ES analyses (Figure 1) [22]. Modifications were based on a previous report that described the adaptation of a 5970 MSD for ES [23], which made use of the resistively heated metal ion sampling capillary [24] and an rf-only ion guide capacitively coupled to the $\mathrm{rf} / \mathrm{dc}$ analyzer quadrupoles [25]. Unique features of the current instrument include the replacement of the single MSD vacuum chamber with a three-stage, differentially pumped system constructed from commercially available vacuum chamber components (Norcal Products, Yreka, CA). The region that contains the 12-in.-long, 0.020-in.-i.d., 0.125-in.-o.d. (High Pressure Equipment, Erie, PA) ion sampling capillary (inserted into an 11in.-long, 0.24-in.-o.d., 0.125-in.-i.d. ceramic tube) and the $0.5-\mathrm{mm}$ orifice skimmer (Beam Dynamics, Minneapolis, $\mathrm{MN}$ ) is pumped by a $13-\mathrm{L} / \mathrm{s}$ rotary pump (Leybold D30A, Export, PA) and has a typical pressure of $450 \mathrm{mtorr}$. The region after the skimmer is pumped by a 700-L/s diffusion pump (Edwards Mk2 160/700, Wilmington, MA) and has a typical operating pressure of $4.5 \times 10^{-5}$ torr. The third region, which contains the analyzer quadrupoles and the $0-$ to $-10-\mathrm{kV}$ high voltage dynode electron multiplier (Phrasor Scientific, Duarte, CA), is pumped by two $60-\mathrm{L} / \mathrm{s}$ (for $\mathrm{N}_{2}$ ) turbomolecular pumps (Balzers TPH 060, Fremont, $\bar{C}$; ; Leybold TMP/NT-50, Export, PA) with a typical pressure of $9.5 \times 10^{-6}$ torr.

Ions are transported from the skimmer to the $\mathrm{rf} / \mathrm{dc}$ analyzer quadrupoles via a set of 9-in.-long, rf-only quadrupole ion guides capacitively coupled to the existing analyzer quadrupoles [23, 25] with nylon screws and $0.125-\mathrm{mm}$ mica spacers. The 9 -in. ion guides are divided into two sets: the first 6 -in. set makes a pressure contact with the second 3 -in. set in the Lexan flange that couples vacuum regions 2 and 3 (Figure 1h). The four rods of the guides are each grounded through a $10-\mathrm{mH}$ rf ind uctor coil. The rf-only guides are divided into two sections to allow the a stainless steel orifice plate to fit between the second and third vacuum regions. Presently, no stainless stee] orifice is in place. The use of two sets of rf-only ion guides also facilitates the ease with which the system 
Table 1. Alkylamine thiohydantoin amino acid derivatives

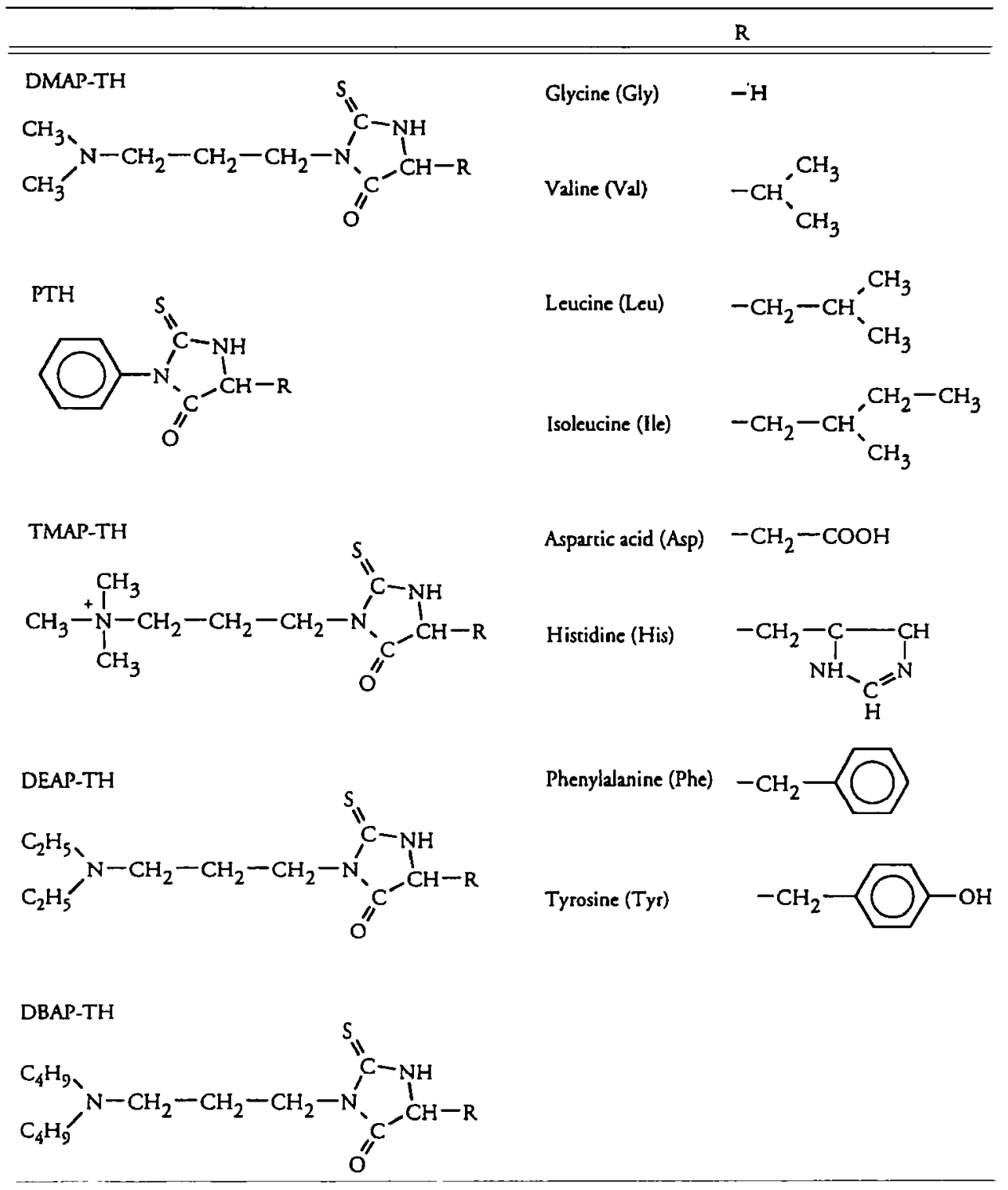

can be assembled and disassembled. Addition of the rf-only ion guides required the removal of 17 turns off each of the rf-coils on the MSD RFPA board to tune the rf-circuit. The instrument also contains custom components machined from the polycarbonate plastic Lexan to support the capillary and skimmer, the $X, Y$ positioning pins of the sampling capillary, the front end of the rf-only ion guides, the ion guide spacers, and the flange that separates vacuum regions two and three. The front flange of the instrument is machined from polyetheretherketone (PEEK) and contains six female banana jack feedthroughs that allow connection of the sampling capillary heater, temperature sensor, and the dc lead to the skimmer. The concentric stainless steel and ceramic tubes of the ion sampling capillary are supported and sealed by using a bored $0.25-0.125$-in. teflon reducing union (Swagelok, Arcadia Valve and Seal, Arcadia, CA).

ES mass spectra were obtained by direct sample infusion by using a syringe pump (Harvard Apparatus Model 22, South Natick, MA) coupled to the ES needle via a $20-\mathrm{cm}$ length of $50-\mu \mathrm{m}-\mathrm{i} . \mathrm{d}$., $350-\mu \mathrm{m}-0 . \mathrm{d}$. fused silica tubing. Samples were infused at a flow rate of $2-5 \mu \mathrm{L} / \mathrm{min}$ and sprayed from a $100-\mu \mathrm{m}-\mathrm{i} . \mathrm{d}$., $300-\mu \mathrm{m}-$ o.d. stainless steel ES needle located $0.5^{-1} \mathrm{~cm}$ from the orifice of the sampling capillary. Improved spray conditions were found if the tip of the ES needle was electropolished prior to use [26]. The $4-5-\mathrm{kV}$ high voltage contact was made at the $1 / 32$-in. zero dead volume stainless steel union (Valco, Houston, TX) used to couple the fused silica transfer line to the ES needle. The degree of CID that occurs in the capillary-skimmer 


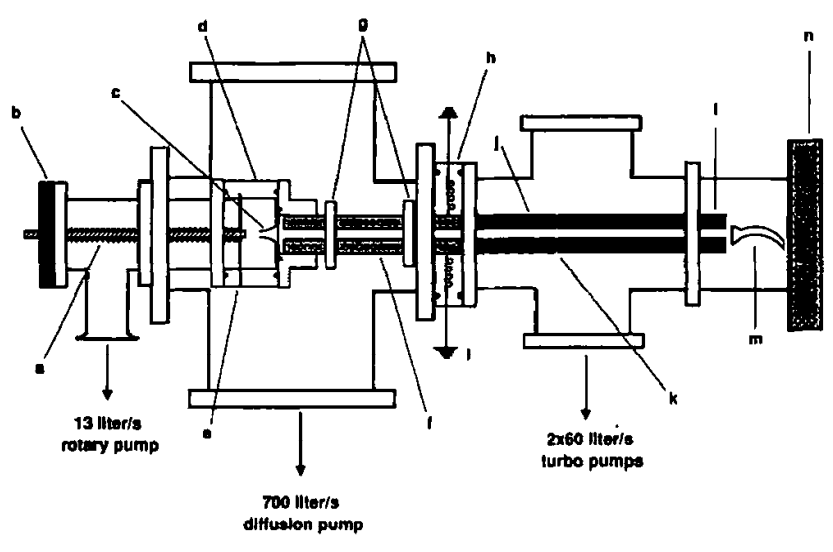

Figure 1. Schematic of the modified ES quadrupole mass spectrometer: (a) heated stainless steel ion sampling capillary; (b) PEEK front flange with six electrical feedthroughs; (c) $0.5-\mathrm{mm}$ skimmer; (d) skimmer-quadrupole support constructed from Lexan; (e) $X, Y$ position pins for sampling capillary; ( $f$ ) first set of rf-only quadrupole ion guides; $(\mathrm{g})$ quadrupole spacers constructed from Lexan; (h) Lexan coupling flange; (i) $10-\mathrm{mH}$ rfinductor coils; (j) second set of rf-only ion guides; (k) $0.125-\mathrm{mm}$ mica spacers; (1) 0-800-u analyzer quadrupoles; (m) 0- to - 10-kV conversion dynode electron multiplier; (n) HP 5970 MSD rf-power supply.

region was controlled by increasing the capillary potential from 28 to $110 \mathrm{~V}$ and maintaining the skimmer at $10 \mathrm{~V}$. ES-MS and SIM mass spectra were collected at resolutions of 0.7 and $1.2 \mathrm{u}$ (full width at half maximum), respectively.

\section{Histograms and Calibration Curves}

Histograms and calibration curves were constructed from the integrated areas of the SIM chromatograms obtained over a 0.8 -u range about the $[\mathrm{M}+\mathrm{H}]^{+}$ions by using $1.5-\mu \mathrm{L}$ filled-loop injections (Rheodyne 7125 injector, Cotati, CA) at a flow rate of $5 \mu \mathrm{L} / \mathrm{min}$. The data were then normalized to the species with the highest response.

\section{Results and Discussion}

\section{Electrospray and Capillary / Skimmer Collision- Induced Dissociation Mass Spectra}

Figure 2 presents the ES mass spectra of DMAPTH-Gly, Val, Asp, and His obtained by using a capillary-skimmer offset of $30 \mathrm{~V}$. The mass-to-charge ratios and relative intensities of the principal ions found in the ES mass spectra of all eight DMAP-TH amino acid derivatives at the same offset voltage are presented in Table 2. The $[\mathrm{M}+\mathrm{H}]^{+}$ion forms the base peak in all the ES spectra except those of DMAP-TH-His and DMAP-TH-Tyr, where the ions at $m / z 237$ and 163 form the base peaks, respectively. The ions at $m / z 61$, 73,102 , and 121 were observed in all background spectra of the methanol-water-acetic acid solvent obtained between sample runs. Formation of the $[\mathrm{M}+$ $\mathrm{H}]^{+}$ions is attributed to protonation of the tertiary nitrogen of the DMAP functional group. This protonation site is supported by the mass-to-charge ratios of the fragment ions observed in the ES spectra of the derivatives obtained at higher capillary-skimmer offset voltages (see following text). The $[\mathrm{M}+2 \mathrm{H}]^{2+}$ ion at $m / z 141.5$ in the mass spectrum of DMAP-TH-His (Figure $2 \mathrm{~d}$ ) is attributed to additional protonation of the imidazole ring. Origins of the ions at $m / z 237$ and 119 are discussed in succeeding text as is the origin of the $m / z 163$ ion in the mass spectrum of DMAP-THTyr.

All the ES mass spectra in Table 2 show ions $45 \mathrm{u}$ less than the corresponding $[\mathrm{M}+\mathrm{H}]^{+}$ion, whereas those of DMAP-TH-Gly, Ile, His, Phe, and Tyr also show ions 73 u less than the $\left[\mathrm{M}+\mathrm{H}^{+}\right.$ion. DMAPTH-His also shows a $[\mathrm{M}+2 \mathrm{H}-45]^{2+}$ ion at $m / z 119$. To determine whether these are fragment or impurity ions, the mass spectra were obtained at a higher capillary-skimmer offset voltage. Figure 3 shows the spectrum of DMAP-TH-Phe obtained by using an offset of $60 \mathrm{~V}$. It can be seen that the relative intensities of the $[\mathrm{M}+\mathrm{H}-45]^{+}(\mathrm{m} / \mathrm{z} 247)$ and $[\mathrm{M}+\mathrm{H}-73]^{+}(\mathrm{m} / \mathrm{z}$ 219) ions increase at the higher capillary potential, which indicates that these are in fact fragment ions. Indeed, complete capillary-skimmer CID breakdown graphs could be constructed by increasing the capillary potential from 28 to $94 \mathrm{~V}$ over the course of a $40-\mathrm{min}$ sample infusion as seen for DMAP-TH-Val in Figure 4. The graph shows distinct dissociation and appearance onsets similar to those seen in mass-selected CID breakdown graphs, which reflects the energy selectivity available in the capillary-skimmer region [27, 28]. Similar onsets also were seen in the capillary-skimmer breakdown graphs constructed for DMAP-TH-Gly, Phe, and Leu [22].

The mass-to-charge ratios and relative intensities of the principal ions found in the capillary-skimmer CID mass spectra of all eight DMAP-TH amino acid derivatives by using an offset of $60 \mathrm{~V}$ are presented in Table 3. Each of the DMAP-TH derivatives gives rise to $[\mathrm{M}+\mathrm{H}-45]^{+}$and $[\mathrm{M}+\mathrm{H}-73]^{+}$ions except DMAP-TH-Asp, which shows $[\mathrm{M}+\mathrm{H}-45]^{+}$and [M $+\mathrm{H}-105]^{+}$ions. DMAP-TH-Gly, Leu, Ile, and Phe also show ions at $[\mathrm{M}+\mathrm{H}-100]^{+}$, whereas DMAPTH-Tyr has the $[\mathrm{M}+\mathrm{H}-145]^{+}$ion at $m / z 163$ ion noted above as its base peak.

Scheme I presents a proposed fragmentation pathway for DMAP-TH amino acid derivatives. The $[\mathrm{M}+$ $\mathrm{H}-45]^{+}$fragment ions are attributed to the loss of neutral dimethylamine $(45 \mathrm{u})$ from the DMAP functional groups whereas the $[\mathrm{M}+\mathrm{H}-73]^{+}$ions arise either from the subsequent loss of ethylene $(28 \mathrm{u})$ from the propyl thiohydantoin amino acid cations or from the direct loss of DMAP from the $[\mathrm{M}+\mathrm{H}]^{+}$ions. Scheme I is based on a previous study of the fragmentation of a series of protonated alkylamines [29] that showed that under low energy CID conditions (laboratory collision energies of 5-100 eV) protonated amines dissociate to produce an alkyl cation by loss of a 

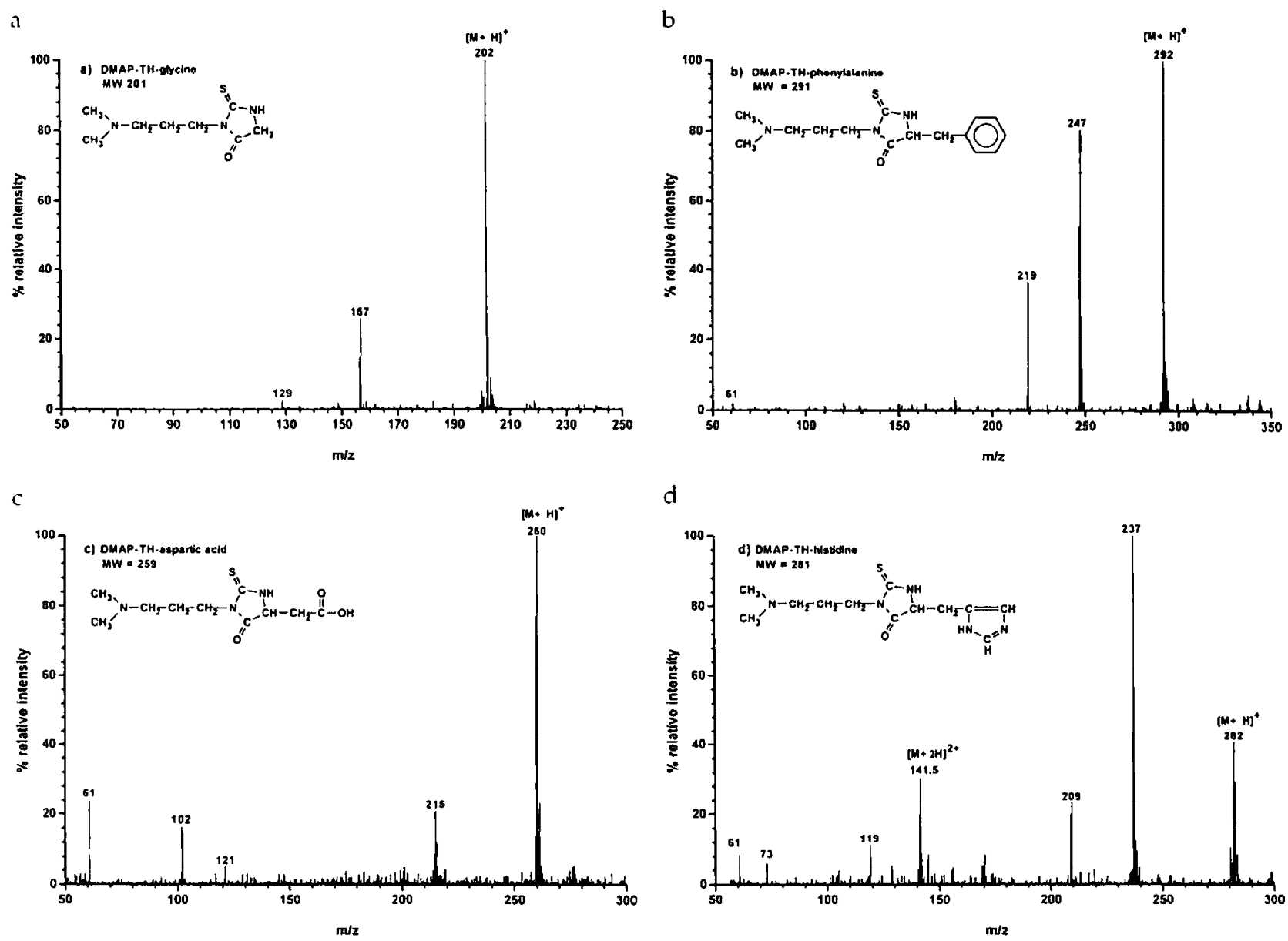

Figure 2. ES mass spectra of (a) DMAP-TH-Gly, (b) DMAP-TH-Phe, (c) DMAP-TH-Asp, and (d) DMAP-TH-His in $50 \%$ methanol-water-1\% acetic acid. The spectra were obtained by using $50-\mathrm{pmol} / \mu \mathrm{L}$ solutions and capillary-skimmer offset of $30 \mathrm{~V}$.

neutral alkylamine and via formation of a protonated amine by loss of an olefin:

$$
\begin{gathered}
{\left[\mathrm{R}_{1} \mathrm{NHR}_{2} \mathrm{R}_{3}\right]^{+} \rightarrow \mathrm{R}_{1}^{+}+\mathrm{NHR}_{2} \mathrm{R}_{3}} \\
{\left[\mathrm{R}_{1} \mathrm{NHR}_{2} \mathrm{R}_{3}\right]^{+} \rightarrow\left[\mathrm{R}_{1}-\mathrm{H}\right]+\left[\mathrm{NH}_{2} \mathrm{R}_{2} \mathrm{R}_{3}\right]^{+}}
\end{gathered}
$$

Reaction 1 was found to be favored for those protonated alkylamines that can form a primary alkyl ion.
For these species, the developing primary alkyl cation rearranges to the more stable secondary or tertiary alkyl ion prior to dissociation. The potential energy released by this exothermic rearrangement reaction increases the tendency of these rearranged ions to dissociate via loss of a neutral amine (reaction 1) [29]. This fragmentation reaction will be favored for the DMAP-TH derivatives because the propyl group can

Table 2. Principal ions in the ES mass spectra of DMAP-TH amino acid derivatives"

\begin{tabular}{ccccccccc}
\hline DMAP-TH & $\begin{array}{c}m / z \\
{[M+H]^{+}}\end{array}$ & $\begin{array}{c}\% \text { rel. } \\
\text { int. }\end{array}$ & $\begin{array}{c}m / z \\
{[M+H-45]^{+}}\end{array}$ & $\begin{array}{c}\% \text { rel. } \\
\text { int. }\end{array}$ & $\begin{array}{c}m / z \\
{[M+H-73]^{+}}\end{array}$ & $\begin{array}{c}\% \text { rel. } \\
\text { int. }\end{array}$ & $\begin{array}{c}m / z \\
{[M+H-145]^{+}}\end{array}$ & $\begin{array}{c}\% \text { rel. } \\
\text { int. }\end{array}$ \\
\hline \hline Gly & 202 & 100 & 157 & 26 & 129 & 2 & - & - \\
Val & 244 & 100 & 199 & 14 & - & - & - & - \\
Leu & 258 & 100 & 213 & 9 & - & - & - & - \\
Ile & 258 & 100 & 213 & 31 & 185 & 5 & - & - \\
Asp & 260 & 100 & 215 & 21 & - & - & - & - \\
His & 282 & 40 & 237 & 100 & 209 & 23 & - & - \\
& 141.5 & 30 & 119 & 12 & - & - & - & - \\
Phe & 292 & 100 & 247 & 80 & 219 & 37 & - & - \\
Tyr & 308 & 82 & 263 & 52 & 235 & 12 & 163 & 100 \\
\hline
\end{tabular}

${ }^{a}$ Obtained by using $50-\mathrm{pmol} / \mu \mathrm{L}$ solutions and a capillary-skimmer offset of $30 \mathrm{~V}$. 


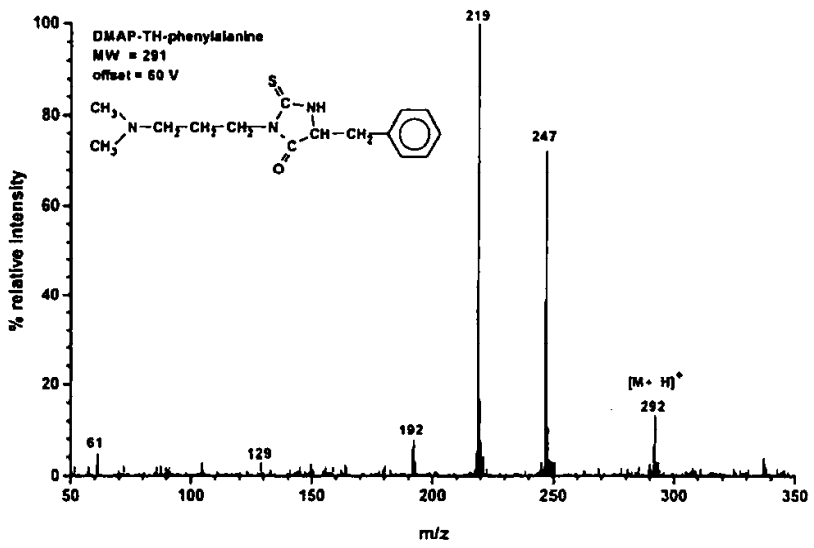

Figure 3. ES mass spectra of DMAP-TH-Phe with a capillary-skimmer offset of $60 \mathrm{~V}$. The spectrum was obtained by using a $50 \mathrm{pmol} / \mu \mathrm{L}$ solution in $50 \%$ methanol-water- $1 \%$ acetic acid.

form a primary alkyl thiohydantoin amino acid cation. Indeed, no ions of $m / z$ t6 that correspond to protonated dimethylamine are seen in any of the DMAP-TH amino acid derivative mass spectra. The origins of the $[\mathrm{M}+\mathrm{H}-45]^{+}$and $[\mathrm{M}+\mathrm{H}-73]^{+}$ions presented in Scheme I were confirmed from the mass-selected CID spectra of DMAP-TH-Phe, Val, Leu, lle, His, and Gly obtained on a TQMS [21].

The $[\mathrm{M}+\mathrm{H}-100]^{+}$fragment ions in the spectra of DMAP-TH-Leu, Ile, and Phe in Table 3 likely arise from the additional loss of $27 \mathrm{u}(\mathrm{HCN})$ due to cleavage and rearrangement of the thiohydantoin ring, or, in the case of DMAP-TH-Leu and Ile, loss of $\mathrm{C}_{2} \mathrm{H}_{3}$ from the respective $\mathrm{R}$ groups. The $[\mathrm{M}+\mathrm{H}-105]^{+}$ion $(\mathrm{m} / \mathrm{z}$ 155 ) in the spectrum of DMAP-TH-Asp may arise from the loss of neutral acetic acid via a hydrogen rearrangement reaction that follows the loss of the neutral dimethylamine. The $[\mathrm{M}+\mathrm{H}-145]^{+}$ion at $\mathrm{m} / z 163$ in the spectrum of DMAP-TH-Tyr may be attributed to cleavage of the thiohydantoin ring of the $[\mathrm{M}+\mathrm{H}]^{+}$ ion between the tertiary nitrogen and the carbonyl and between the thiocarbonyl and the secondary nitrogen

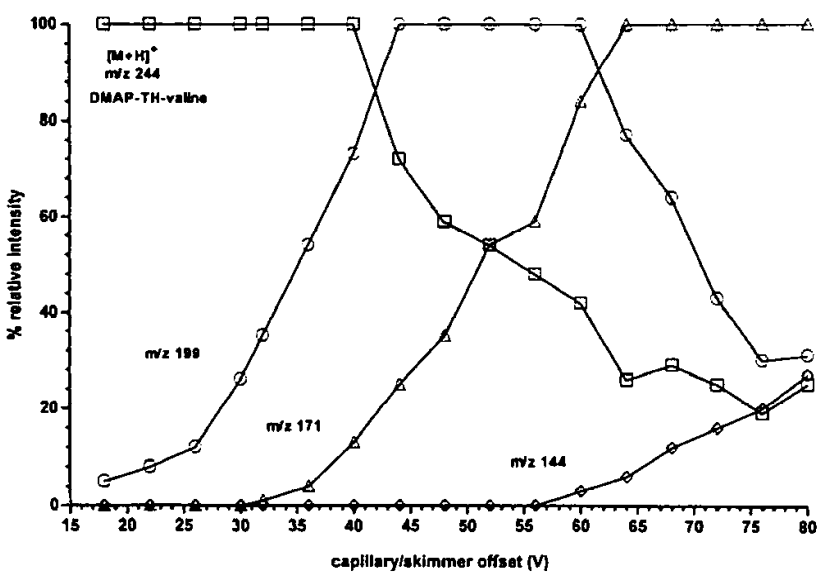

Figure 4. Complete capillary-skimmer CID breakdown graph of DMAP-TH-Val constructed by increasing the offset from 18 to $84 \mathrm{~V}$.
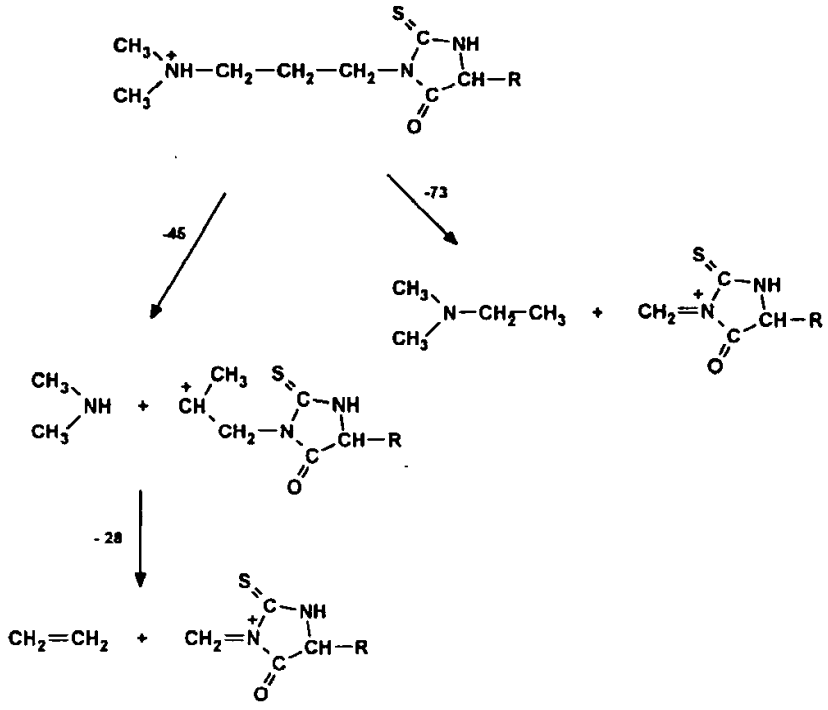

Scheme I.

with the charge retention on the fragment that contains the $\mathrm{R}$ group. Corresponding cleavages of the $[\mathrm{M}+\mathrm{H}$ $-45]^{+}$(loss of $100 \mathrm{u}$ ) and the $[\mathrm{M}+\mathrm{H}-73]^{+}$(loss of 72 u) fragment ions also could result in the formation of an ion of $m / z 163$. Similar cleavages of the thiohydantoin rings were used to rationalize the fragment ions observed in the EI-MS spectra of the $\mathrm{M}^{+}$ions [5] and of the fragment ions observed in the thermospray mass spectra of the $[\mathrm{M}+\mathrm{H}]^{+}$ions [6] of a series of PTH amino acid derivatives. However, in both these studies, it was postulated that the charge be retained on the fragment that contains the phenyl as opposed to the $R$ group. Further mass-selected CID studies are required to fully elucidate the fragmentation pathway of the $[\mathrm{M}+\mathrm{H}]^{+}$ion of DMAP-TH-Tyr.

It is of interest to note that although differences do exist in relative intensities of the $[\mathrm{M}+\mathrm{H}]^{+}$and $[\mathrm{M}+$ $\mathrm{H}-45]^{+}$and $[\mathrm{M}+\mathrm{H}-73]^{+}$and $[\mathrm{M}+\mathrm{H}-100]^{+}$ ions of DMAP-TH-Leu and Ile (Table 3), they are not significant enough to differentiate the isomers. This indicates that chromatographic separation may be required to separate the Leu and Ile derivatives prior to mass spectrometry analysis in any sequencing schemes based on the alkylamine thiohydantoin derivatives $[17,18]$.

The conclusion that the DMAP-TH derivatives fragment via the loss of neutral dimethylamine also is supported by the capillary-skimmer CID mass spectra of TMAP-TH-Phe, DEAP-TH-Phe, and DBAP-TH-Phe obtained at an offset of $80 \mathrm{~V}$ (Table 4). It can be seen that these derivatives also fragment by loss of the neutral amine, that is, the $m / z 247$ ions in the spectra of TMAP-TH-Phe, DEAP-TH-Phe, and DBAP-TH-Phe correspond to the $[\mathrm{M}-59]^{+}$(loss of trimethylamine), $[\mathrm{M}+\mathrm{H}-73]^{+}$(loss of diethylamine), and $[\mathrm{M}+\mathrm{H}-$ $129]^{+}$(loss of dibutylamine) ions, respectively. The three Phe derivatives also show ions at $m / z 219,28 u$ less than the $m / z 247$ ions, similar to those seen for 
Table 3. Principal ions in the capillary-skimmer CID mass spectra of DMAP-TH derivatives"

\begin{tabular}{|c|c|c|c|c|c|c|c|c|c|c|c|c|}
\hline OMAP-TH & $\begin{array}{c}m / 2 \\
{[M+H]}\end{array}$ & $\begin{array}{l}\% \text { rel. } \\
\text { int. }\end{array}$ & $\begin{array}{c}m / 2 \\
{[M+H-45]}\end{array}$ & $\begin{array}{l}\% \text { rel. } \\
\text { int. }\end{array}$ & $\begin{array}{c}m / z \\
{[M+\mathrm{H}-73]}\end{array}$ & $\begin{array}{l}\% \text { rel. } \\
\text { int. }\end{array}$ & $\begin{array}{c}m / z \\
{[M+H-100]^{\dagger}}\end{array}$ & $\begin{array}{l}\text { \% rel. } \\
\text { int. }\end{array}$ & $\begin{array}{c}m / z \\
{[M+H-105]}\end{array}$ & $\begin{array}{l}\% \text { rel. } \\
\text { int. }\end{array}$ & $\begin{array}{c}m / 2 \\
{[M+H-145]}\end{array}$ & $\begin{array}{l}\text { \% rel. } \\
\text { int. }\end{array}$ \\
\hline$\overline{\text { GIV }}$ & 202 & 35 & 157 & 100 & 129 & 31 & - & - & - & - & - & - \\
\hline Val & 244 & 33 & 199 & 100 & 171 & 93 & - & & - & - & - & - \\
\hline Leu & 258 & 76 & 213 & 100 & 185 & 88 & 158 & 12 & - & - & - & - \\
\hline Ile & 258 & 41 & 213 & 100 & 185 & 91 & 158 & 6 & - & - & - & - \\
\hline Asp & 260 & 62 & 215 & 100 & - & - & - & - & 155 & 94 & - & - \\
\hline \multirow[t]{2}{*}{ His $^{6}$} & 282 & 16 & 237 & 32 & 209 & 67 & - & - & - & - & - & - \\
\hline & 141.5 & 9 & 119 & 15 & - & & - & - & - & - & - & - \\
\hline Phe & 292 & 14 & 247 & 73 & 219 & 100 & 192 & 9 & - & - & - & - \\
\hline Tyr & 308 & 23 & 263 & 44 & 235 & 34 & - & -- & - & - & 163 & 100 \\
\hline
\end{tabular}

"Obtained by using $50-\mathrm{pmol} / \mu \mathrm{L}$ solutions and a capillary-skimmer offset of $60 \mathrm{~V}$.

Base peak attributed to an impurity found at $m / z 149$.

the DMAP-TH derivatives. The $[\mathrm{M}+\mathrm{H}-147]^{+}$ion at $m / z 229$ in the spectrum of DBAP-TH-Pe may be attributed to the loss of both the $R$ group of Phe (91 u) and one butyl group of DBAP with an accompanying $\mathrm{H}$ transfer to the thiohydantoin cation. It is interesting to note that the spectrum of DBAP-TH-Phe also shows an ion at $m /=157$ that corresponds to the dibutylaminoethyl cation. DBAP-TH-Phe was the only derivative in this study that fragmented to form a tertiary amine cation.

The observation that the alkylamine thiohydantoin derivatives give rise to $[\mathrm{M}+\mathrm{H}]^{+}$ions that fragment in a well-defined manner in the capillary-skimmer region and that the degree of fragmentation can be controlled and used in future protein sequencing methods based on ES-MS detection via a bench-top mass spectrometer. ES-MS detection schemes that make use of the optimum CID offset voltage can target more than one ion characteristic of the various amino acid derivatives and in so doing increase the degree to which the amino acid derivatives can be differentiated and identified. The relatively facile fragmentation of the alkylamine thiohydantoin derivatives in the capillary-skimmer region can be compared to the harsh collision conditions ( $70 \mathrm{eV}$ and a target thickness of $7 \times 10^{14}$ atoms $\left./ \mathrm{cm}^{2}\right)$ in the collision cell of the TQMS required to fragment the PTH 311 derivatives [17].

\section{Relatioe Integrated Peak Areas}

Relative integrated peak areas of the $[\mathrm{M}+\mathrm{H}]^{+}$ions of DMAP-TH-Asp, Gly, Tyr, Val, Leu, and Phe (normalized to that of DMAP-TH-Phe) obtained by using 15 pmol of injected sample and a capillary-skimmer offset of $20 \mathrm{~V}$ are presented in Figure 5. If we assume that the errors in the measured responses of DMAPTH-Asp, Gly, Tyr, and Val are equal to that of DMAPTH-Phe, then it can be seen that the responses of DMAP-TH-Tyr, Val, and Leu agree within experimental error. However, a substantially lower response is found for DMAP-TH-Asp and an overall higher response is measured for DMAP-TH-Phe. Complete calibration curves for DMAP-TH-Asp, Gly, and Phe were constructed and the following relative sensitivities were determined over the linear of range of 150 to 3750 fmol: DMAP-TH-Asp, 100 counts $/$ fmol $\left(R^{2}=0.991\right)$; DMAP-TH-Gly, 900 counts $/ \mathrm{fmol}\left(\mathrm{R}^{2}=0.987\right)$; DMAPTH-Phe, 1700 counts $/$ fmol $\left(R^{2}=0.985\right)$. The calibration curves provide a more complete measure of the DMAP-TH amino acid responses over a wider concentration range and confirm the trend in relative responses observed in Figure 5. The corresponding limits of detection (LOD, $3 \sigma$ ) for DMAP-TH-Asp, Gly, and Phe are on the order of 1000, 500, and $200 \mathrm{fmol}$, respectively. These LODs are an order of magnitude

Table 4. Principal ions in the capillary-skimmer CID mass spectra of the DMAP-TH-Phe, TMAP-TH-Phe, DEAP-TH-Phe, and DBAP-TH-Phe"

\begin{tabular}{|c|c|c|c|c|c|c|c|c|}
\hline \multirow[b]{2}{*}{ Assignment } & \multicolumn{2}{|c|}{ DMAP-TH-Phe } & \multicolumn{2}{|c|}{ TMAP-TH-Phe } & \multicolumn{2}{|c|}{ DEAP-TH-Phe } & \multicolumn{2}{|c|}{ DBAP-TH-Phe } \\
\hline & $m / z$ & $\begin{array}{c}\% \text { rel. } \\
\text { int. }\end{array}$ & $m / z$ & $\begin{array}{c}\% \text { rel. } \\
\text { int. }\end{array}$ & $m / z$ & $\begin{array}{c}\% \text { rel. } \\
\text { int }\end{array}$ & $\mathrm{m} / \mathrm{z}$ & $\begin{array}{l}\% \text { rel. } \\
\text { int. }\end{array}$ \\
\hline Molecular ion & 292 & 20 & 306 & 15 & 320 & 95 & 376 & 100 \\
\hline Loss of amine & 247 & 60 & 247 & 100 & 247 & 100 & 247 & 40 \\
\hline Loss of amine $+\mathrm{C}_{2} \mathrm{H}_{4}$ & 219 & 100 & 219 & 15 & 219 & 35 & 219 & 18 \\
\hline Other ${ }^{b}$ & 192 & 25 & - & - & - & - & 229 & 15 \\
\hline & - & - & - & - & - & - & 157 & 7 \\
\hline
\end{tabular}

\footnotetext{
OObtained by using 50-pmol/ $\mu \mathrm{L}$ solutions and a capillary-skimmer oftset of $80 \mathrm{~V}$.
}

bee text. 
higher than those measured in the ES-MS study of the PTH 311 derivatives [17], and several orders of magnitude more sensitive than the 50-pmol levels reported in the thermospray mass spectrometry study of the PTH amino acids [6].

Differences in the relative responses of the DMAP$\mathrm{TH}$ amino acid derivatives can be rationalized in terms of a recent model for ion formation during the ES process [26]. In this model, the analytical sensitivity, or flux of ions from the droplet surface, is dictated, in part, by the diffusion of the solute species to the charged surface of the droplet and by the activation energy barrier that the species must then surmount to be "free" of the droplet surface. Diffusion of the solute is determined only by concentration gradients, whereas the activation barrier is determined by the relative solvophobicity of the ion in the solvent employed. In general, the greater the solvophobicity of the ion, the lower the activation barrier it must surmount and the greater the overall anticipated analytical sensitivity [30].

The responses of the six DMAP-TH amino acid derivatives seen in Figure 5 increase as the relative solvophobicity of the amino acid functional group increases, that is, DMAP-TH-Asp is the least solvophobic and has the lowest overall response, whereas the most solvophobic derivative, DMAP-TH-Phe, gives rise to the highest overall response. The remaining DMAP-TH derivatives follow the general trend of increasing response for those derivatives with polar but uncharged functional groups (Gly, Tyr), to somewhat higher responses from those with nonpolar functional groups (Val, Leu, Phe). This trend of increasing response with increasing solvophobicity of the amino acid R group also was noted in the ES-MS studies of the PTH 311 amino acid derivatives [18].

Further evidence of an increase in ES response with an increase in the solvophobicity of the amino acid derivative is found in the relative peak areas of the $[\mathrm{M}+\mathrm{H}]^{+}$ions of the DMAP-TH, DEAP-TH, and DBAP-TH derivatives of $P$ he and the $\mathrm{M}^{+}$ion of TMAP-TH-Phe obtained under identical spray conditions (Figure 6). Once again, the most solvophobic DBAP-TH-Phe derivative gives rise to the highest overall response. The anticipated increase in the response of DEAP-TH-Phe relative to that of DMAP-THPhe is not observed, however. In this instance, an increase from 7 to 11 carbons in the alkylamine group may not be sufficient to produce a significant increase in response. (An increase from 8 to 16 carbons was required to measure a fourfold increase in the ES signal of a series of tetraalkyl ammonium halides [30].) Further studies of the relative responses of the DMAPTH, DEAP-TH, DBAP-TH, as well as that of the tripropylamino-TH derivative, in different solvent systems are required to establish a more significant trend. However, the overall higher response for DBAP-THPhe observed in these preliminary studies indicates that the DBAP-TH amino acid derivatives are the most

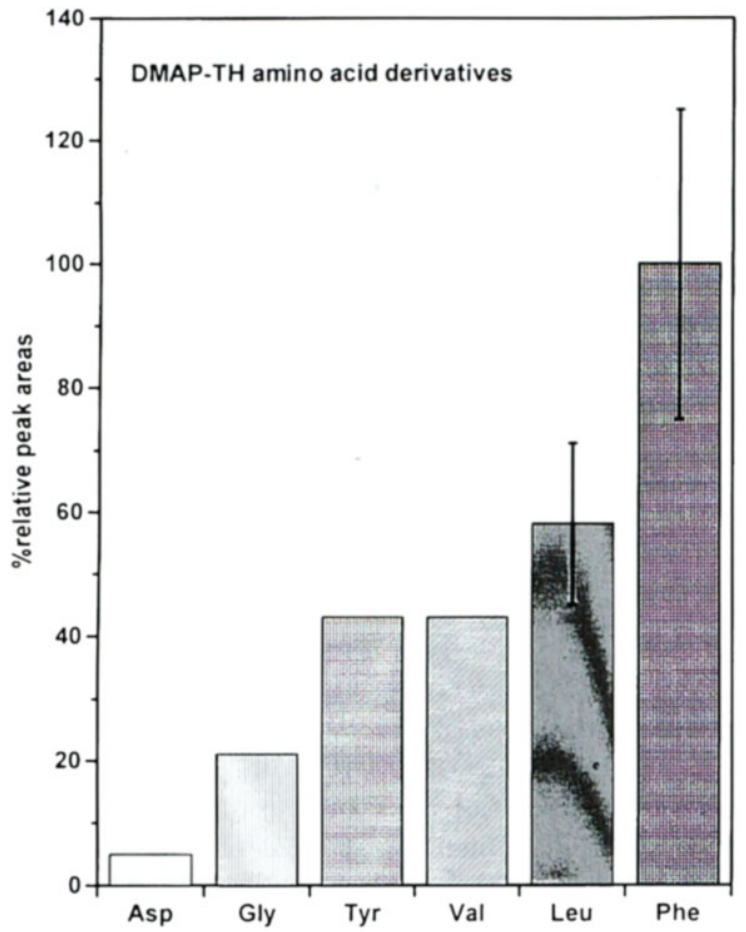

Figure 5. Relative peak areas of the $[\mathrm{M}+\mathrm{H}]^{+}$ions of the DMAP-TH-amino acid derivatives from 15 pmol of injected sample. The error bars are the sample standard deviation of triplicate injections.

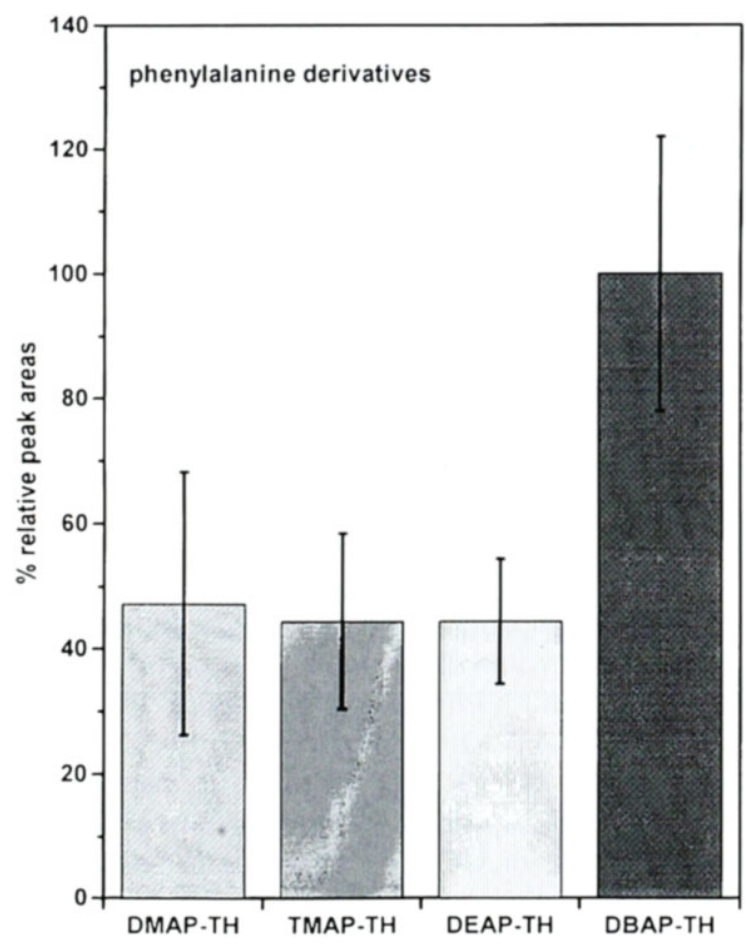

Figure 6. Relative peak areas of the $[\mathrm{M}+\mathrm{H}]^{+}$ions of the DMAP-TH, DEAP-TH, and DBAP-TH derivatives of Phe and the $\mathrm{M}^{+}$ion of TMAP-TH-Phe from 15 pmol of injected sample. The error bars are the sample standard deviation of triplicate injections. 
viable candidates in the development of Edmanlike protein sequencing methods with ES-MS detection.

It is interesting to note that DMAP-TH-Phe and the quaternary amine derivative TMAP-TH-Phe give rise to similar ES responses (Figure 6). Indeed, complete calibration curves for the DMAP-TH and TMAP-THPhe lead to sensitivities of 1100 counts $/ \mathrm{fmol}\left(R^{2}=\right.$ $0.985)$ and 1300 counts $/$ fmol $\left(R^{2}=0.945\right)$, respectively, over the linear range of 100 and $1500 \mathrm{fmol}$. The approximately equal sensitivities of DMAP-TH-Phe and TMAP-TH-Phe indicate that tertiary alkylamine amino acid derivatives can give rise to responses that are comparable to those of quaternary amines if a sufficiently acidic solvent is employed. Moreover, the twofold greater response measured for DBAP-TH-Phe relative to that of TMAP-TH-Phe (Figure 6) indicates that the solvophobicity of the derivative can play a greater role in determination of the overall ES response than that played by a functional group that is precharged in solution.

The relative responses of the alkylamine thiohydantoin derivatives illustrate that the solvophobicity of the amino acid-end product is an important factor in the design of sequencing methods based on ES-MS detection. The need for an ES-active site on the end-product amino acid derivatives capable of carrying a charge is, however, also a critical factor to consider, as indicated by the relative sensitivities measured for the DMAPTH-Phe and PTH-Phe under identical spray conditions. A sensitivity of only 25 counts $/ \mathrm{fmol}\left(\mathrm{R}^{2}=0.991\right)$ was obtained over the linear range $2000-76,000 \mathrm{fmol}$ of PTH-Phe, that is, the analysis of DMAP-TH-Phe is approximately 50 times more sensitive than that of the $\mathrm{PTH}$ derivative.

\section{Conclusions}

The present study of a series of alkylamine thiohydantoin amino acid derivatives leads to several important considerations in the design of future protein sequencers with ES-MS detection. Each of the alkylamine thiohydantoin derivatives gives rise to a well-defined $[\mathrm{M}+\mathrm{H}]^{+}$ions as well as characteristic fragment ions upon CID. The facile fragmentation of derivatives in the capillary-skimmer region of the mass spectrometer precludes the need for the harsh fragmentation conditions required by the PTH 311 derivatives in the collision cell of a TQMS [17]. This allows the design of multiple ion monitoring schemes on a bench-top ES mass spectrometer that will lead to an increased ability to identify the amino acid end-products after each sequencing cycle. Because differentiation of the DMAP-TH-Leu and Ile derivatives is not possible based on the ES-MS or capillary-skimmer CID spectra alone, some form of chromatographic separation of the sequencer end-products will be required prior to ES-MS analysis.

Differences in the relative ES responses of the eight DMAP-TH derivatives with changing solvophobicity of the amino acid $\mathrm{R}$ group must be considered in any future protein sequencing schemes based on ES-MS detection. This is not unlike the differing sensitivities to the PTH amino acids experienced in the UV detection currently employed in Edman sequencing methods $[14,15]$. The approximately equal ES sensitivities of the DMAP-TH and TMAP-TH-Phe derivatives in an acidic solvent $(\mathrm{pH}=3)$ indicate that derivatization with a tertiary alkylamine group can lead to responses that are comparable to those obtained by using a quaternary amine amino acid derivative. Uncharged tertiary alkylamine derivatives would avoid the need to covalently couple the protein to the sequencing support required when quaternary amine [19] or highly polar [16] end-products are employed. As such, it may be possible to find extraction conditions that will permit recovery of the derivative from the sequencer support at the end of each sequencing cycle without also washing off the remainder of the protein.

Finally, preliminary studies that show the increased response of DBAP-TH-Phe relative to that of the DMAP-TH-Phe under identical solvent conditions indicate that even greater ES-MS sensitivities may be achieved as the solvophobicity of the alkylamine group increases. Increasing the mass of the alkylamine offers the additional advantage of further removal of the $[\mathrm{M}+\mathrm{H}]^{+}$and characteristic fragment ions from the low mass chemical noise often encountered in ES analyses. Given a detection limit of $200 \mathrm{fmol}$ for DMAPTH-Phe, and an approximately $50 \%$ greater response of DBAP-TH-Phe relative to DMAP-TH-Phe, it is anticipated that the detection limits of the DBAP-TH derivatives on a single quadrupole mass spectrometer will be comparable to those reported for the PTH 311 amino acid derivatives on a TQMS [17]. Future efforts to couple an Edmanlike protein sequencer to a benchtop ES mass spectrometer will therefore be focused on a DBAP-TH amino acid derivatives.

\section{Acknowledgments}

We would like to thank Tim Wachs of Cornell University, John Mahoney and Steve Ruatta of Phrasor Scientific, Bill Cusworth of the University of Washington, and Mike Davis and Doug Stahl of the City of Hope for helpful discussions during the instrument design. We thank Miro Rusnak of Biomedical Instrumentation Services, City of Hope, for the design and construction of the variable voltage power supply as well as many helpful discussions. Special thanks to Anne Thomas for her initial work in the design of the future vacuum protection system. This work was supported in part by grants from the National Institutes of Health (CA33572; RR06217, GM51728). C.B. gratefully acknowledges a fellowship from Amgen Corporation, Thousand Oaks, CA. Hewlett-Packard, Palo Alto, CA, is acknowledged for donation of the MSD 5970 mass spectrometer and other instrument components.

\section{References}

1. Hagenmaier, H.; Ebbighausen, W.; Nicholson, G.; Votsch, W. Z. Naturforsch. 1970, 25b, 681 . 
2. Fairwell, T.; Barnes, W. T.; Richards, F. F.; Lovins, R. E. Biocle'mistry 1970, 9, 2260.

3. Sun, T.; Lovins, R. E. Anal. Biochem. 1972, 45, 176-191.

4. Fairwell, T.; Brewer, H. B. Anul. Biochem. 1980, 107, 140-149.

5. Melvas, B. W. Actn Chrm. Scan. 1969, 23, 1679-1684.

6. Pramanik, B. C.; Hinton, S. M.; Millington, D. S.; Dourdeville, T. A.; Slaughter, C. A. Anal. Bioche'm. 1988, 175, 305-318.

7. Fairwell, T.; Lovins, R. E. Biochem. Biophlys. Res. Commmun. 1971, 43, 1280-1289.

8. Fairwell, T.; Ellis, S.; Lovins, R. E. Anal. Biochtm. 1973, 53, 115-123.

9. Rangarajan, M.; Ardrey, R. E.; Darbre, A. J.Chromatogrr. 1973, $87,499-512$.

10. Suzuki, T.; Song, K.-D.; Itagaki, Y.; Tuzimura, K. Org. Mnss Spectrom. 1976, 11, 557-568.

11. Okada, K.; Sakuno, A. Org. Mass Spectrom. 1978, 13, 535-539.

12. Edman, P. Actn Ch'm. Scan. 1950, 4, 283-293.

13. Edman, P.; Begg, G. Eur. 1. Bioch'm. 1967, 1, 80-91.

14. Hewick, R. M.; Hunkapiller, M. W.; Hood, L. E.; Dreyer, W. J. 1. Biol. Chom. 1981, 256, 7990-7997.

15. Calaycay, J.; Rusnak, M.; Shively, J. E. Anal. Biochem. 1991, 192, 23-31.

16. Stolowitz, M. L.; Hood, L.; Kim, C. S. J. Protein Ch'nt. 1992, 11, 360-361.

17. Bures, E. J.; Nika, H.; Chow, D. T.; Morrison, H. D.; Hess, D.; Aebersold, R. Anal. Biochem. 1995, 224, 364-372.

18. Hess, D.; Nika, H.; Chow, D. T.; Bures, E. J.; Morrison, H. D.; Aebersold, R. Antt. Biochem. 1995, 224, 373-381.
19. Aebersold, R.; Bures, E. J.; Namchuk, M.; Goghari, M. H.; Shushan, B.; Covey, T. C. Protein Sci. 1992, 1, 494-503.

20. Bailey, J. M.; Tu, O.; Basic, C.; Shively, J. E.; Lee, T. D. In Tothiques in Protein Clemistry V; Crabb, J. W., Ed.; Academic Press: San Diego, CA, 1994; pp 169-178.

21. Basic, C.; Bailey, J. M.; Lee, T. D.; Shively, J. E. Proceedings of the 41st ASMS Conference on Mass Spectrometry and Allied Topics; May 31-June 4, 1993; Abstract 588a.

22. Basic, C.; Davis, M. T.; Stahl, D. S.; Lee, T. D. Proceedings of the +2nd ASMS Confercence on Mass Spectrometry and Allied Topics; May 29-June 3, 1994; p 1020.

23. Duffin, K. L.; Wachs, T.; Henion, J. D. Anal. Chem. 1992, 64, 61-68.

24. Chowdury, S. K.; Katta, V.; Chait, B. T. Rapit Commmm. Mass Spectrom. 1990, 4, 81-87.

25. Brubaker, W. M. In Adzance's in Mass Spectrontetry, Vol. 4; Kendrick, E., Ed.; Elsevier: Amsterdam, 1968; pp 293-299.

26. Chowdhury, S. K.; Chait, B. T. Anal. Chem. 1991, 63, 1660-1664.

27. Katta, V.; Chowdhury, S. K.; Chait, B. T. Anal. Chem. 1991, 6.3, 174-178.

28. Voyksner, R. D.; Pack, T. Rapid Commmu. Mass Spectrom. 1991, 5, 263-268.

29. Reiner, E. J.; Harrison, A. H.; Bowen, R. D. CmI. I. Chem. 1989, 67, 2081-2088.

30. Fenn, J. B. /. Am. Soc. Mass Spectrom. 1993, 4, 524-535. 